\title{
Contronymy and Semantic Primes
}

\begin{abstract}
Contronymy, that is sense opposition invoked by one word, can pose a serious conundrum from a theoretical standpoint. Nonetheless, the prime concern of this paper is to introduce the phenomenon into a broader discussion within theoretical linguistics. To be more specific, the question at hand is: what kind of comprehensive and coherent theoretical construct can be adequate for semantic representation of contronymy? It will be demonstrated that the particular sense opposition can be classified as being linked with direct negation. A theoretical vantage point will be presented that addresses the cause of opposition via the means of the natural semantic metalanguage theory. This approach may shed some light on how to deal with the problem from a cognitive perspective. The underlying methodological assumptions of the presented framework, based on the idea of semantic primes, prove to be a coherent tool for encapsulating radical sense opposition manifested by contronyms. As an addendum to this prolegomena there will also be presented a brief discussion of some of the implications of contronymy for fields such as the theory of the human mind, natural language processing, artificial intelligence, machine translations and big data structures.
\end{abstract}

Keywords: contronymy, sense opposition, primitive concepts, semantic primes, negation, natural semantic metalanguage theory.

What is frequently assumed about natural language is that it is to a fair degree different from formal languages and formal systems in general. On an interesting opening note, as Wolniewicz (1980: 7) pointed out, it can be stated that the whole opposition of natural language vs. artificial/ constructed/formal language is somewhat skewed, as the modifier 'natural' in the latter may imply that symbolic logic and mathematics are somehow less natural, or at least man-made. This, however, is not the case, as logical laws and their imperatives seem no less natural, in the sense that they are discovered rather than designed. This can be considered as an aspect that is shared by both natural and formal languages alike. Another example of the misunderstanding is the assumption that formal languages are fully explicit whereas natural languages simply are not. Yet, for example in the "language" of mathematics, polysemy is not uncommon. The symbol of minus may mean the operation of subtraction or indicate a negative number. Although the two ideas are linked at least intuitively, and the syntax of a mathematical equation resolves the ambiguity, the polysemy is quite obvious. A similar idea is present in programming languages under the term operator overloading, where programmers can reassign the semantics of an operator based on certain rules. Even so, what one would expect form a formal system is that one sign/word of that system would 
not convey opposite meanings, especially within a syntactic context. This is, however, the case when it comes to natural languages. The phenomenon of contronymy, which is the prime concern of this paper, is based on the idea that two opposite senses may be evoked by one word. To give an example one can examine the verb 'to seed' and come to the conclusion that it can be used in two opposite meanings: 1) as the action of putting seeds into some sort of object, or 2) as an action that is based on removing seeds. Therefore, such an instance may be used to show a strong opposition between human languages and formal languages(or formal systems in general), as contronyms, as will be shown on further pages, also preserve their particular polysemy within well-formed phrases and sentences. To show what properties a mathematical equivalent would have to possess to mimic entities like contronyms, one may consider a minus sign, '-', which can be used to symbolize not only subtraction, but also an idea that would contradict subtraction, such as addition, and moreover all of that within a full blown equation. Such a situation seems to be uncommon to say the least within arithmetic or formal/programming languages, and it is hardly imaginable that such singularity would be of any use.

The existence of the phenomenon of contronymy leads to questions about how distant natural languages are from formal languages, and whether formal methods are suitable for the analysis of English, Polish, or any ethnic language. The idea of such stark sense opposition at first may seem difficult to capture from a strict theoretical perspective. Nonetheless, as will be demonstrated, contronymy may be conceptually linked to negation, and by this token can be summarized and brought together using precise terminology. The main thread depicted here will lead to conclusions on what type of theoretical approach may be adequate for the natural language, and also what kind of impact contronymy may have on disciplines other than theoretical linguistics that would demand general cohesion.

To briefly show the significance of this phenomenon in a contemporary context, suffice it to say that within big data structures it is not uncommon to have contradictory objects. Computer software that has as its very purpose processing such structures, or even inferring on the basis of such constructs (automated reasoning), has to somehow cope with the inconsistencies. Contronyms will be presented as an example of such a predicament. Any linguistic system that holds in its dictionary entries like the verb 'to seed' has to manifest serious consistency problems.

The paper will be concluded with a brief illustration of a theoretical approach to contronyms that seems viable. Natural semantic metalanguage theory (NSM), developed and promulgated by cognitive linguists Anna Wierzbicka and Cliff Goddard, considering its particular characteristics that will be depicted in the last but one section, is conceptually compelling. Semantic primes employed by the discussed theory include the logical operator of negation in the form of the concept NOT. With the use of this elemental particle of meaning it is possible to provide explications of contronyms using the natural semantic metalanguage, an approach that by definition does not use signs/words that evoke opposite senses. Additionally, the discussed framework of NSM theory enables us to look at the human mind as a coherent system, despite the existence of words that can be summed up as examples of antilogy. 


\section{Contronymy}

Within the discipline of linguistics in recent years the phenomenon of two opposite senses concealed under one lexical unit has been examined to some extent, although only from the descriptive perspective (see Karaman 2008). As Karaman puts it: "That such a phenomenon exists in natural language is, according to some researchers, unthinkable since it seems to be an impossibility that a linguistic sign could signify ideas which contradict each other" (Karaman 2008: 173). In light of those words a question comes to mind: what type of theoretical construct can account for the contradictions embedded in one single word in a coherent way? Yet, before presenting a systemic approach to the discussed singularity, the general characteristics of the phenomenon have to be brought forward.

Words that possess opposite senses are labelled in the literature under terms such as: 'contronyms', 'antilogies', 'auto-antonyms', 'two-faced words', 'Janus words' and many more. All those terms are treated as synonyms, although there are substantial differences among members of this category. Karaman (2008: 175) proposes labelling the whole phenomenon under the umbrella term 'contronymy' and dividing it into subcategories that would account for the alterations, such as contronymy based on antonymy, incompatibility, reversivity, complementarity and conversivity. This is due to a broad definition that groups all members that have the discussed sense opposition which states as follows: "Contronymy is a form of polysemy that can be defined as sense opposition at the micro-level. This occurs when a minimum of two senses of a polysemous lexical item contradict each other" (Karaman 2008: 175).

For the purposes of this paper the presentation will be limited to a few subcategories. At interest here are sense oppositions, such as those based on complementarity, incompatibility, as well as reversivity, although it can be claimed that the results are equally adequate for all contronyms ${ }^{1}$.

The first example is a contronym based on reversivity in the form of the verb 'skinned', which can be used in opposite senses:

(1) John skinned the banana.

(2) John skinned the sofa.

The polysemy based on reversivity, defined here, however, intuitively, is apparent and is based on the idea of a process that has two directions, and spans two opposite terminal states (Karaman 2008: 184, 185). In the first sentence the meaning of the phrase revolves around removing the skin of the banana, whereas in the second one it is applying the skin that is relevant. Therefore, the verb can be used in two opposite ways: (S1) to express the removal of something, and (S2) to express applying something. To add to the general descriptive analysis conducted by Karaman, I would like to signify that one meaning also indicates the negation of the other. The acceptance of the sense (S1) implies

1 For a broader presentation of typology of contronyms, also with regard to antonymy, see Karaman (2008) and Klégr (2013). 
that the negation of (S2) is true, as applying something means not removing the very same thing, and vice versa. When it comes to sentence (2), however, it is possible to imagine that somebody is actually removing the skin from a leather sofa. Therefore, for example in sentence (2), it is possible that the same sentence may describe two actions simultaneously where one implies the negation of the other.

The deeper idiosyncrasy of this verb can be brought forward by analysing it in the form of a predicate-argument structure. If the verb 'skinned' is treated as a monotransitive verb, as in the above examples (1) and (2), both senses have the same (as it is called within linguistics) valency, with the positions for the subjects and direct objects filled accordingly. Increasing the number of arguments and treating it as a ditransitive verb, by for example introducing some sort of instrument in the form of a prepositional object, will not remove the discussed opposition. Therefore, there is little to say about the nature of this stark polysemy by analysing the structure of the sentence, or to be more precise, when it comes to the argument structure of the verb. This is especially evident while imagining that one sentence can be understood in two opposite ways. Hence, approaches that are based upon the predicate-argument structure will suffer in situations such as the one described above. It has to be stressed that such methods are prevalent among cognitive linguistics and are frequently employed in natural language processing as well as artificial intelligence: theories such as case theory (Fillmore 1968), frame semantics (Fillmore 1976) or construction grammar (Goldberg 1995) to name a few. It is worth noting that the combination of the two latter theories was already implemented in natural language processing and reasoning (see Minsky 1975 and Spranger, Suchan, Bhatt 2016). In this sense the idea of a frame can provide the necessary background of non-linguistic knowledge that is relevant for interpreting the language structure (what kind of instrument is proper for removing and what kind of instrument is proper for applying skin to an object, etc.). In this case the ambiguous structure is filled by praxeological knowledge. The same scenario and analysis applies to other verbs that exhibit opposition to remove/ deprive of vs. to add/yield, just like the verb 'to seed' mentioned in the beginning of the article.

Another interesting example is the word 'screen'. It may be considered as an example of a contronym based on incompatibility. This category is defined by Karaman (2008: 178) as "terms which denote classes sharing no members. This lexical element can be used regarding things that have opposite functions". The lexeme 'screen' can therefore reference an object that allows a certain observer to see a particular phenomenon, just as in the sentence below:

(3) The phenomenon $y$ can be seen because of the screen.

Simultaneously, its opposite meaning can be detected when an object shields the observer from a phenomenon:

(4) The phenomenon $y$ cannot be seen because of the screen. 
Therefore, 'screen' may refer to things that have the function of showing something (television screen), or of shielding from something (smoke screen). Within the English language the difference of meaning cannot be mapped to the morphological structure. The root of the word 'screen' creates inflections such as 'screened', where the discussed singularity also persists.

(5) The phenomenon $y$ can be seen because it is screened.

(6) The phenomenon y cannot be seen because it is screened.

A slightly different situation however may be observed if the word 'screen' in sentence (5) would be supplemented by a different preposition, as in 'The phenomenon y can be seen on the screen'. Therefore, syntax can be at work when it comes to the disambiguation of this particular unit. On the other hand, if there is insufficiency of string structure, the ambiguity arises, as in:

\section{(7) $Y$ is screened.}

In this case there is clear ambiguity in the form of two potential opposite senses, and yet again the first meaning implies the negation of the other, as showing something by the means of something means not concealing something using the same thing.

The next few examples are based on mutually exclusive binary pairs (binary opposition). Examples of such contronyms (in the sense of imposing contradiction) can be shown by employing negative affixation to certain verbs or adjectives. For instance, English safety labels often explicitly enumerate together 'flammable' and 'inflammable' warnings on combustible materials, due to the fact that the prefix 'in-' may be incorrectly interpreted as changing the meaning of 'flammable' to 'not flammable'. Such lexical entities have the meaning that can be summarised with the use of symbolic logic as $x$ and $\neg \mathrm{x}$.

Another such example, one that again might be significant when it comes to machine translations, is the contronym 'periodic' with its low-profile ambiguity. Consider the following sentence coming from Karaman (2008: 181):

(8) Periodic outbreaks of the disease are inevitable.

Depending on how accustomed the reader is with the word 'periodic' he can interpret the instance of an outbreak either as happening regularly (S1), or in an irregular manner (S2). Therefore, the relation between two senses is contradictory. Again, the discussed contronym bares the character of direct negation. Only after short pondering does it become hard to believe that outbreaks of disease happen at stable intervals. However, this cannot be treated as an inference based on linguistic knowledge. 
The final example again comes from Karaman (2008: 183). At the micro-level, contronymy of complementary is the most extreme type of sense-opposition, and this time the preposition 'around' can be used in two distinct senses:

(9) S1: My beta fish is swimming around the bowl.

(10) S2: We sat around the table.

As Karaman $(2008: 183,184)$ elaborates: "In the above examples we can observe a clear boundary between the two senses. In S1, around can be associated with 'the satellite object is part of the pivotal object' (i.e. 'the satellite object is in the interior of the pivotal object'), whereas in S2 it can be associated with 'the satellite object is not part of the pivotal object' (i.e. 'the satellite object is on the exterior of the pivotal object')". This instance illustrates the idiosyncratic character of the natural language in a very clear way. Contronymy of complementarity is an example of stark binary sense opposition. The author also cites a more mathematical explication of the nature of this type:

Within aspect $A$ there are the lexical elements $a 1, a 2, \ldots a 1$ is complementary with $a 2$ if from the existence of $a 1$ the non-existence of $a 2$, from the existence of $a 2$ the non-existence of $a 1$, from the non-existence of a1 the existence of $a 2$, and from the non-existence of $a 2$ the existence of a1 can be concluded." (Lutzeier 2007, quoted after Karaman 2008: 183)

Again, the discussed phenomenon manifests itself in the form of negation, as for the word 'around' if $\mathrm{S} 1$ is true, it implies that $\neg \mathrm{S} 2$ is true, and vice versa.

As shown, the discussed sense opposition is closely linked to negation. This is due to the fact that one contronym possesses two senses that are related in such a way that one is, or implies, the negation of the other. It is easy to recognize that within one database entries like 'screen', 'periodic', or 'around', in the way that they function in the natural language, have to lead to conflicts. It is also apparent that the risk of the logical error of equivocation, that is the situation when one term is used in two opposite senses, is therefore substantial. It has to be stressed, however, that the fact that those words can have highly fluctuating meanings (even from one extreme to the other) does not mean that those words can mean anything, or that in linguistics "everything goes". The range of possible senses of a word still has a limited scope that can be precisely accounted for from the perspective of cognitive linguistics.

\section{Contronyms and other sense relations and features}

Contronymy is also an interesting topic from the perspective of other sense relations and their features. The phenomenon was analyzed in this manner by Klégr (2013) under the label of enantiosemy. The definition of the term used in the mentioned article is: "A case of *polysemy in which one sense is in some respect the opposite of another" (Matthews 1997: 122). Klégr gives an elaborate explanation on exactly why this sense relation should be classified within the realm of poly- 
semy. First of all, there are at least two meanings, therefore monosemy is excluded. The two relevant senses are without a doubt related, therefore homonymy is also not applicable. Additionally, it cannot be said that vagueness is a feature of those meanings. The possible interpretations that fall under the scope of a contronym are clear. Hyponymy and hypernymy, although they are also polysemous categories that can have multiple word-internal sense relations (for example 'pear' understood as a tree or a fruit), also logically do not seem plausible comparans, not to mention synonymy.

Antonymy, on the other hand, seems the most intuitively related semantic concept to contronyms. Some of the types of relations are indeed shared by antonyms and contronyms (directionality, converseness, etc., see Karaman 2008; Klégr 2013). Although the phenomenon of contronymy is word-internal compared to the typical word-external opposites, some analysis can be carried out on both levels. This is to say that typical antonymy is a sense relation between two distinct and yet opposite words like hot/cold, whereas contronymy has the same opposite sense relation, but in reference to just one word. Therefore, the link between the two is there. As Klégr (2013: 19) puts it: "The fact that the same set of relations operate between and within lexical items is no doubt of cognitive significance". The question that rises is whether, and if so to what extent, contronymy can be subjected to similar analysis as antonymy. Markedness would be a feature that comes to mind of antonymous pairs that could be applied. Yet again, it is another example of the difficulties that one encounters during examination of contronymy. Unlike in antonymy over two distinct words (hot/ cold), or with the use of morphological negation (happy/unhappy, honest/dishonest etc.), there is no difference in the form of the two meanings. Therefore, the apparent differences between antonymy and contronymy may have an impact on the applicability of tests for markedness. In fact it seems impossible to examine whether one sense may be dominant or broader than the other when it comes to contronyms. Lehrer (1985: 398) gave an example of a useful tool that allows the identification of a marked member of the antonymy pair. It has to be noted that here antonymy is understood in the narrow, technical sense as an example of a sense opposition that has a gradable scale between the two extremes. Let's consider the questions 'How happy are you?' and 'How unhappy are you?', which reveal that the negative form carries an additional meaning that is not present in the first. This is to say that the negative form implies that the person asked is actually unhappy, and the question is just about the level of his unhappiness. The positive form does not hold this supposition (the marked member of the relation is neutralized). Sentences like 'How custom was the service?' ('custom' understood as a common practice, or a special treatment) seem not viable for such analysis.

On the other hand, Lehrer (1985: 399) provides a useful way of identifying the marked member of the antonym pair that can be used for contronyms. This can be done with the use of sentences that discuss proportions and ratios, as in:

$$
\begin{aligned}
& \text { John is }\left\{\begin{array}{l}
\text { twice } \\
\text { half }
\end{array}\right. \text { as tall as Bill. } \\
& \text { *Sally is }\left\{\begin{array}{l}
\text { twice } \\
\text { half }
\end{array}\right. \text { as short as Sue. }
\end{aligned}
$$


By applying the same device to the contronym 'fast' (referring to either something moving quickly or something solid and unable to move) as in the sentence: 'John is twice/half as fast as Bill' only one meaning is preserved, and that is the one revolving around quick movement ${ }^{2}$. Therefore, features of antonymy such as markedness can be, at least partially, subject to similar analysis as antonymy.

On a similar note, in some cases the meaning of a contronym can be limited to only one of the possible senses by concatenating a negative prefix. For example, words like 'to unbolt' (with the opposition of 'to bolt' as in to secure/to flee) or 'to unbuckle'('buckle' - connect, or break or collapse) have only one meaning.

One of the meanings of the pair of opposites can also bear more distinctive features over the other. An example of such a case would be the verb 'to skin', already discussed in the previous section, where one of the senses may exhibit a different valency in special circumstances, and in that sense can be grammatically marked. Klégr (2013: 14) provides additional information that supplements the analysis conducted earlier on the verb 'to skin':

In some (...) verbs enantiosemy is associated with in/transitivity; the intransitive meaning of the cow milks / the wound soon skinned is connected with the absence of the object due to the incompatibility of the subject with the agentive role. The opposite meaning is associated with transitivity: this use primarily results from the meaning of the verb which determines what can function as the object.

Another instance would be the derivation of the verb 'to screen', also mentioned previously. In the Polish language this derivation possesses only one sense (the verb can only be used when something is used to block some sort of phenomenon). Additionally, the use of this verb is rather technical, and is therefore significantly marked by frequency.

Another possible emanation of contronymy that should be mentioned is the use of two opposite senses under one lexical unit as a rhetorical device or as a colloquial, euphemistic or ironic expression. An example of such a type would be the use of the word 'amazing' when something went wrong, or using the phrase 'you're bad' in a situation when somebody achieved success. Klégr comments on this phenomenon in the following words:

Nevertheless, there is a fundamental difference between a rhetorical figure of speech and antonymous polysemy, a trope being a contextual use based on ad hoc interaction which expresses the intended meaning by an implicature, while enantiosemy presupposes the existence of two distinct lexical units. (Klégr 2013: 12).

In light of the above comment, the rhetoric/ironic devices were and will be excluded from further analysis in this paper. For deeper analysis see (Klégr 2013: 15, 16).

2 It has to be noted that this example of a contronym does not manifest a gradable scale compared to the word 'custom'. For more details on markedness and antonymy see Lehrer (1985). 


\section{Natural Semantic Metalanguage Theory (NSM)}

As mentioned earlier, the topic of contronymy has not yet been addressed via a "global" theory of language. Therefore, the main aim of this paper is to employ a linguistic theory that has gained some recognition in the literature to account for the discussed extreme sense opposition, namely Natural Semantic Metalanguage theory (NSM). It can serve as an illustration of how the phenomenon can be approached from the cognitive linguistics standpoint. The semantic primes/ primitive concepts that this theory employs may be used to explicate the meaning of contronyms without falling into contradictions. This is due to the fact that the concepts of the natural semantic metalanguage have, by definition, only one distinct meaning. In essence NSM theory defines the human mind as a system that is based on coherent and consistent units of meaning and their combinations. The dictionary of the natural semantic metalanguage, although it may express all the meanings of any ethnic language, in essence consists of fewer words than any ethnic language. The multiplicity of meanings, including those that are contradictory, can be formed by combining the meanings of the semantic primes that are in core non-contradictory. The language of thought that is composed of the elementary particles of meaning, or lingua mentalis as Wierzbicka would put it (see Wierzbicka 1980), in the light of NMS theory is a consistent and explicit structure in that particular sense. As the proponents of this approach claim, this is a comprehensive approach to the semantics of the natural language (see Goddard 2003), and therefore the use of this theory may be considered as an expansion on what already has been done within the analysis of contronymy.

Just to give a brief outline of this framework, suffice it to say that it is a principle of tertium comparationis for the juxtaposition of different ethnical languages. Because of the fact that this theory uses primitive concepts that are supposed to be innate, it is a useful tool to circumvent the problems of ethnocentricity, and also a few other difficulties in constructing lexicons such: circulus in definiendo, and regressus ad infinitum (see Wierzbicka 1996: 11; Goddard and Wierzbicka 2001: 183). The particular characteristics of the framework discussed here can also help to solve other issues such as those raised by the existence of contronyms.

Anna Wierzbicka associates the main foundations of this theory with Leibniz's concept of the "alphabet of human thought". This is to say that all languages contain a palette of elementary units of meaning that are so clear and intuitive that they do not require any definition (Wierzbicka 1996: 11). For instance, the particle SEE, just as the particle KNOW (which was apparent to Descartes) are so elementary for human cognition that to give a satisfactory definition of this unit is unthinkable (Wierzbicka 1996: 48). Therefore, NSM theory postulates the existence of a finite set of universal concepts that is an intersection over the sets of all concepts of all ethnical languages. Moreover, this pallet of semantic primes is stable, native among human beings, and its members may be combined to form more geometrico complex meanings.

One of the more recent accounts on the set of natural semantic metalanguage units includes particles such as (Goddard 2012: 712-715): 
Table 1. The set of NSM units

\begin{tabular}{|c|c|}
\hline I, YOU, SOMEONE, SOMETHING-THING, PEOPLE, BODY & substantives \\
\hline KIND, PART & relational substantives \\
\hline THIS, THE SAME, OTHER ELSE & determiners \\
\hline 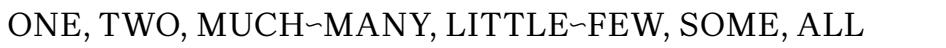 & quantifiers \\
\hline GOOD, BAD & evaluators \\
\hline BIG, SMALL & descriptors \\
\hline KNOW, THINK, WANT, FEEL, SEE, HEAR & mental predicates \\
\hline SAY, WORDS, TRUE & speech \\
\hline DO, HAPPEN, MOVE, TOUCH & $\begin{array}{l}\text { actions, events, movement, } \\
\text { contact }\end{array}$ \\
\hline $\begin{array}{l}\text { BE (SOMEWHERE), THERE IS, HAVE (SOMETHING), } \\
\text { BE (SOMEONE/SOMETHING) }\end{array}$ & $\begin{array}{l}\text { location, existence, } \\
\text { possession, specification }\end{array}$ \\
\hline LIVE, DIE & life and death \\
\hline $\begin{array}{l}\text { WHEN } \text { TIME, NOW, BEFORE, AFTER, A LONG TIME, } \\
\text { A SHORTTIME, FOR SOME TIME, MOMENT }\end{array}$ & time \\
\hline $\begin{array}{l}\text { WHERE PLACE, HERE, ABOVE, BELOW, FAR, } \\
\text { NEAR, SIDE,INSIDE }\end{array}$ & space \\
\hline NOT, MAYBE, CAN, BECAUSE, IF & logical concepts \\
\hline VERY, MORE & intensifier, augmentor \\
\hline LIKE $\backsim A S \backsim W A Y$ & similarity \\
\hline
\end{tabular}


The sets of elementary units of meaning undergo evolution. However, according to leading researchers within the field, the power of this set should not exceed 100 elements (Goddard and Wierzbicka 2001: 185).

For reasons of limited space not all units can be discussed here, and the remarks will be limited to the most important unit of NSM from the perspective of this article - namely the particle NOT. The concept of negation was not included in the early literature concerning natural semantic metalanguage theory (cf. Wierzbicka 1980). Initially, Wierzbicka thought that although all the evidence pointed to the fact that the concept of negation is universal, meanings like 'don't want', or the idea of 'diswant' should not be considered cognitively primal and primitive. Wierzbicka initially sought to tie the meaning of the unit with the unit WANT, as that would solve many problems regarding the disproportions between the meaning of 'want' and 'don't want' and 'know' and 'don't know' ('don't want' may mean that somebody does not want something that much, and does not have to necessarily mean that he/she does not want that something at all). However, this approach proved to be unsatisfactory in the long run. Finally, the factor that tipped the scales was the evidence on how quickly and adequately children in the early stages of language acquisition use concepts related to direct negation (see Wierzbicka 1996: 89-91). Data pointed to the interpretation that NOT is used in a discreet and combinatorial way in the sense that it is separated from other concepts.

To recapitulate, in essence, the particles of the natural semantic metalanguage can be understood similarly to the prime numbers in mathematics. That is the numbers that are members of the natural numbers category greater than 1 , and cannot be expressed by multiplying two smaller natural numbers. And conversely, a finite sequence of the products of prime numbers may be used to form any natural number that is not a prime number. Therefore, a natural number greater than 1 that is not prime is called a composite number. Moreover, every natural number that is not a prime number can be factorized as a product of primes. Consequently, prime numbers can be regarded as equivalents of the primitive particles of meaning used in NSM theory, and composite numbers as compound concepts. The aim of this section is to demonstrate that those atoms of meaning may also be used to explicate contradictory words present in particular ethic languages, and this is where the analogy between mathematics and natural language breaks down.

Within NSM theory, contronyms regain their clear and intuitive interpretation. This is due to the fact that by definition the units of NSM are the elementary particles of meaning, which means that they possess only one meaning, and in that sense the dictionary of this theory is consistent. The most important particle of the NSM set for expressing the sense opposition is the logical concept NOT. This cognitive analogue of the logical operator of negation positioned within the definition of a lexical unit can account for sense opposition as well as contradictions congenital in contronyms. For example, in regard to the word 'screen' in the perspective of NSM, it is possible to denote a shared set of universal particles as well as its feature that accounts for the difference in two discussed senses. That is the substantive SOMETHING, mental predicate SEE, non-mental predicate IS, and the imagination and possibility unit IF... WOULD. The difference between the 
two senses comes from the innerplacement of the additional shared unit, the logical concept NOT that is contained in one of the possible interpretations of the word 'screen'. In this chain of reasoning it is possible to reconstruct two compound concepts of the lexical unit that are as follows:

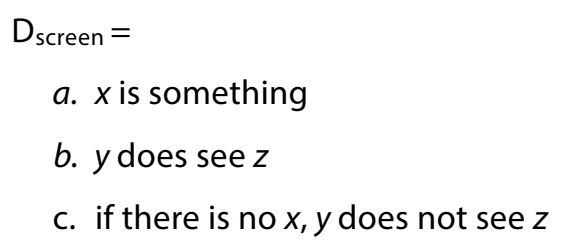

$D_{\text {screen' }}=$
a. $x$ is something
b. $y$ does not see|hear $z$
c. if there is no $x, y$ does see|hear $z$

Although the senses of the two compound concepts are based on an antilogy, in the metalanguage they contain not only a common set of NSM units, but also, to an extent, a common set of strings of NSM units. The difference in meaning comes from two universal particles, NOT and SEE, that form a relation that is the source of polysemy. Consequently, two of those senses, within the English language, may connect to different syntactic structures regarding the prepositions 'on' and 'because of'. Interestingly, for the definition to be complete another unit has to be added, namely the particle HEAR. However, it can only supplement the second meaning of the word 'screen' that stands for an obstruction of sound. In other words, when it comes to auditory functions of the human body the word 'screen' can represent only one meaning. Nonetheless, the particle NOT within the natural semantic metalanguage may serve to reproduce the sense oppositions of the discussed contronym.

Another interesting example is the contronym 'periodic', as its sense opposition is based on the contradiction between the concepts of 'regularity' and 'irregularity', or 'not regularity'. The definitions are as follows:

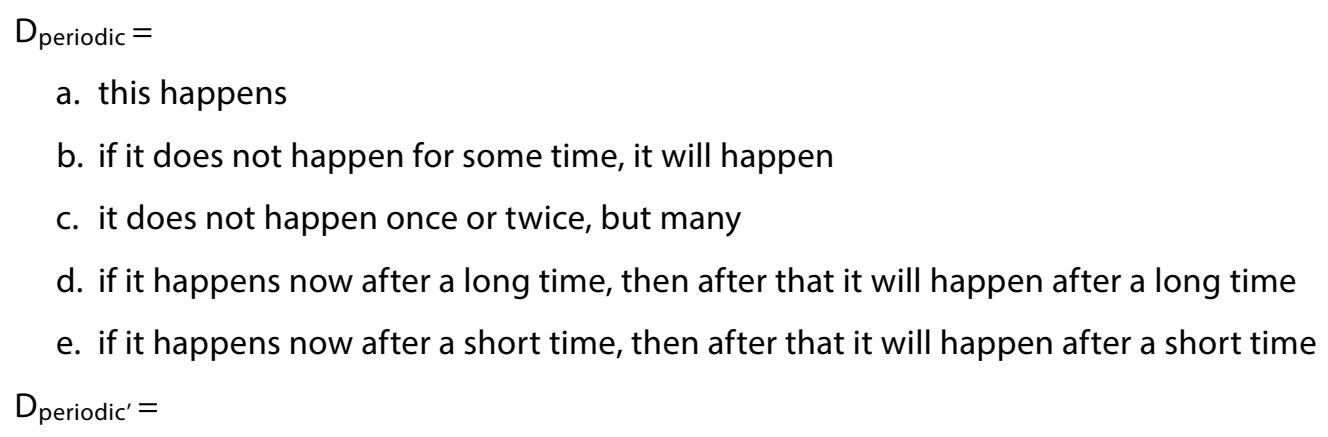
a. this happens
a. if it does not happen for some time, it will happen
a. it does not happen once or twice, but many 
a. if it happens now after a long time, then after that it will not happen after a long time

a. if it happens now after a short time, then after that it will not happen after a short time

As depicted by the above explications the sense opposition can again be brought together by negation. Component (a) indicates that it is an event, (b) that it is not instantaneous (duration is involved), and it happens repeatedly, (c) that it happens many times, and both (d) and (e) define whether those events happen in the same increments of time or not.

The preposition 'around' can also be analysed in this framework, although its meaning is slightly more complicated. This is due to the fact that to express the idea of roundness it is necessary to use the so called semantic molecule. While the investigations conducted within the framework of NSM theory expanded, it began to be apparent that plausible explications of many of the elements of the lexicon require the usage of more complex structures than just the primes and universals (Goddard 2012: 10). This is where the notion of semantic molecules comes into play. The members of this category are still divisible into combinations of primes of NSM and may be used as stepping stones when direct explication by the atoms of meaning is not possible. Nonetheless, the two opposite senses of the discussed polysemy of different types can still be reproduced with unequivocal and unambiguous primes of natural semantic metalanguage, and the differences between them can yet again be mapped to the placement of the logical concept NOT. This also includes morphosyntactic contronyms such as 'inflammable'. Wierzbicka (1996: 223) gives an elaborate description of the semantic molecule of fire, which if associated with some sort of object and particle, the NOT may also be clearly defined. Due to the nature of the explications available via the means of NSM, it is feasible to assume that this approach will be successful in relation to all contronyms.

\section{Conclusions}

This paper aimed to show the idiosyncrasies of natural language in the form of contronyms and their explication by means of sematic primes. The existence of the discussed sense opposition may prove to be problematic in the fields of not only theoretical linguistics but also natural language processing, artificial intelligence or machine translation. However, the phenomenon may be tackled by means of natural semantic metalanguage theory, which has proved to be successful on the grounds of cognitive linguistics.

When it comes to NSM theory, although one can observe "a trend towards increased systematisation and formalisation" (Goddard 2008: 2), it has not yet been formalized in a sufficient way to be viable in the field of computer science. However, if not this particular theory, then any other framework that would use primitive semantic carriers of meaning might prove successful. The work of the members of the so-called Moscow School of Semantics (see Apresjan 1992, 2000; Mel'čuk 1981) was based on similar principles and has already received attention in practical applications within the field of IT (see Fähndrich 2014 et al.). Nonetheless, the outline presented in this paper may become fruitful considering the claims of the major proponents of NSM theory, 
which is "arguably approaching the standard expectations of a formalized metalanguage for natural language" (Goddard 2006: 544).

As a side note it can be said that contronyms help position natural language against formal systems such as formal languages, for example. In this perspective the natural language tends to have sense relations that are opposite to each other concealed behind one lexeme, and this radical polysemy can also be preserved in fully fledged sentences. This is definitely not a common behaviour among formal systems and, as mentioned at the beginning of the article, can be used as an example showing the stark differences between those systems and ethnic languages. However, one interesting to note fact is that from the perspective of NSM theory, the metalanguage embedded in all ethnic languages is in those terms similar to formal systems, as in this perspective the substance of lingua mentalis is based on semantic primes that have one meaning only. In other words, from this cognitive perspective it is possible to treat the human mind, at least on the level of semantics, as a coherent and non-contronymous system that is not based on antilogy.

To demonstrate the significance such entities like contronyms one may point to the project NELL (Never-Ending Language Learning system). This semantic machine learning system, developed by a research team at Carnegie Mellon University, was programmed to mimic the way humans absorb new data. It is supposed to learn by reading the content of the world wide web. The model of inferences is based upon: “(...) an initial ontology defining categories (e.g., Sport, Athlete) and binary relations (e.g., Athlete Plays Sport (x,y))" and "approximately a dozen labeled training examples for each category and relation (e.g., examples of Sport might include the noun phrases "baseball" and "soccer")" (Mitchell et al.). Grounded on such input the program is supposed to “(...) extract, or read information from the web to populate a growing structured knowledgebase, and (...) learn to perform this task better than on the previous day" (Carlson et al.). It becomes apparent that the inconsistencies caused by the phenomenon of contronymy within the natural language, if not dealt with correctly, must have an impact on projects like NELL. Nonetheless, the phenomenon is undoubtedly an interesting topic, showing the intricacies not only of language itself but also of human cognition, that calls for further investigation.

\section{References}

Apresjan, Jurij. 2000. Systematic Lexicography, trans. Kevin Windle, Oxford: Oxford University Press.

Carlson A., Betteridge J., Kisiel B., Settles B., Hruschka E.R., Mitchell T.M. 2010. Toward an Architecture for Never-Ending Language Learning. Proceedings of the Twenty-Fourth AAAI Conference on Artificial Intelligence (AAAI'10),1306-1313.

Fähndrich, J., Ahrndta S., Albayraka S. 2014. Formal Language Decomposition into Semantic Primes. Advances in Distributed Computing and Artificial Intelligence Journal 3.8, 56-73.

Fillmore, Charles J. 1968. The case for case. In: Emmon. Bach \& Robert T. Harms (eds.), Universals in Linguistic theory, New York: Holt Rinehart and Winston, 1-88. 
Fillmore, Charles J. 1976. Frame semantics and the nature of language. Annals of the New York Academy of Sciences, Conference on the Origin and Development of Language and Speech 280, 20-32.

Goddard, Cliff 2003. Thinking across Languages and Cultures: Six Dimensions of Variation. Cognitive Linguistics 14 (2-3), 109-140, DOI: https://doi.org/10.1515/cog1.2003.005.

Goddard, Cliff 2006. Natural Semantic Metalanguage. In: Keith Brown (ed.), The Encyclopedia of Language and Linguistics. 2nd edition. Amsterdam/Heidelberg: Elsevier.

Goddard, Cliff. 2007. Semantic molecules. In: Ilana Mushin \& Mary Laughren (eds.), Selected Papers of the 2006 Annual Meeting of the Australian Linguistic Society at: http://espace.uq.edu.au/. Goddard, Cliff. 2008. Natural Semantic Metalanguage: The State of the Art. In: Cliff Goddard (ed.), Cross-Linguistic Semantics. Amsterdam/Philadelphia: John Benjamins Publishing Company, $1-34$.

Goddard, Cliff. 2010. The Natural Semantic Metalanguage Approach. In: Bernd Heine \& Heiko Narrog (eds.), The Oxford Handbook of Linguistic Analysis, Oxford: Oxford University Press, 459-484.

Goddard, Cliff. 2012. Semantic primes, semantic molecules, semantic templates: Key concepts in the NSM approach to lexical typology. In: Maria Koptjevskaja-Tamm \& Martine Vanhove (eds.), Linguistics. Special issue on "Lexical Typology", 50(3), 711-743, DOI: https://doi.org/10.1515/ ling-2012-0022.

Goddard, Cliff, Wierzbicka, Anna. 2001. Język, kultura i znaczenie: semantyka międzykulturowa. In: Elżbieta Tabakowska (ed.), Kognitywne podstawy języka i językoznawstwa. Kraków: Towarzystwo Autorów i Wydawców Prac Naukowych Universitas, 175-202.

Goldberg, Adele. E. 1995. Constructions: A Construction Grammar Approach to Argument Structure. Chicago/London: The University of Chicago Press.

Karaman, Burcu. I. 2008. On Contronymy. International Journal of Lexicography 21 (2), 173-192.

Klégr, Aleš 2013. The limits of polysemy: enantiosemy. Linguistica Pragensia 2, 7-23.

Lehrer, Adrienne. 1985. Markedness and Antonymy. Linguistics 21, 397-429.

Lutzeier, Peter R. 2007. Wörterbuch des Gegensinns im Deutschen. Band 1: A - G. Berlin/New York: Walter de Gruyter.

Matthews, Peter H. (ed.). 1997. The Concise Oxford Dictionary of Linguistics. Oxford/New York: Oxford University Press.

Mel'čuk, Igor A. 1981. Meaning-Text Models: A recent trend in Soviet linguistics. Annual Review of Anthropology 10, 27-62.

Minsky, Marvin. 1975. A Framework for Representing Knowledge. In: Patrick Henry Winston (ed.), The Psychology of Computer Vision, New York: Mvgraw-Hill, 211-277.

Mitchell, T., Cohen W., Hruschka E., Talukdar P., Betteridge J., Carlson A., Dalvi B., Gardner M., Kisiel B., Krishnamurthy J., Lao N., Mazaitis K., Mohamed T., Nakashole N., Platanios E., Ritter A., Samadi M., Settles B., Wang R., Wijaya D., Gupta A., Chen X., Saparov A., Greaves 
M., Welling J. 2015. Never-Ending Learning. Proceedings of the Conference on Artificial Intelligence (AAAI). Association for the Advancement of Artificial Intelligence (www.aaai.org). Spranger, M., Suchan J., Bhatt M. 2016. Robust Natural Language Processing - Combining Reasoning, Cognitive Semantics and Construction Grammar for Spatial Language. Proceedings of the Twenty-Fifth International Joint Conference on Artificial Intelligence (IJCAI-16), DOI: arXiv:1607.05968 (12 April 2018).

Wierzbicka, Anna. 1980. Lingua Mentalis. The Semantics of Natural Language. Sydney/ New York/ London/ Toronto/San Francisco: Academic Press Australia

Wierzbicka, Anna. 1996. Semantics. Primes and Universals, Oxford,New York: Oxford University Press.

Wolniewicz, Bogusław. 1980. Języki i kody. In: Adam Schaff (ed.), Zagadnienia socjo- i psycholingwistyki. Wrocław: Polska Akademia Nauk, Instytut Filozofii i Socjologii, Zakład Narodowy Imienia Ossolińskich, Wydawnictwo Polskiej Akademii Nauk. 